\title{
Enterprise Value Evaluation Based on FCFF Model - A Case Analysis of Beixinyuan Company
}

\author{
Yanqing Dong ${ }^{1,2, \text { a }}$ \\ 1. College of accounting, Nanjing University of Finance \& Economics, Nanjing 210023, China. \\ 2. Hubei product innovation management research center, Wuhan 430070, China.
}

a1271353079@qq.com

Keywords: Enterprise value evaluation; FCFF model; Free Cash Flow; Beixinyuan Company.

\begin{abstract}
In the current international evaluation industry, the evaluation of enterprise value has developed rapidly and has been highly concerned by the governments and scholars of various countries. There are three basic valuation methods of enterprise value assessment, namely cost method, income method and market method. After development, a series of specific evaluation techniques have been derived. Among them, the most mature and scientific method is the income approach, and the most widely used model in the income approach is the Free Cash Flow of Firm (FCFF). The free cash flow method covers information comprehensively, which can objectively and comprehensively reflect the ability of enterprises to create value, and help enterprises to have a correct understanding of their market value. Based on the actual situation of Beixinyuan Software Co., Ltd., this paper describes in detail the use of free cash flow method to assess the enterprise value of Beixinyuan Software Co., Ltd. in order to judge the value of this company.
\end{abstract}

\section{Introduction}

At present, the valuation of enterprises has become an important aspect concerned by scholars both at home and abroad. Moreover, scholars at home and abroad have done a lot of research on the evaluation of enterprise value by free cash flow method. Tan Hanmei (2016), a domestic scholar, discussed the relevant methods of enterprise valuation. He thought that cash flow discounting method can best reflect the value of enterprises, and the cash flow discounting method is only suitable in the growth and maturity stage. Sun Yanhua (2016) on the free cash flow discount model is discussed, combined with the specific circumstances of the listed companies in our country, between the free cash flow and enterprise value associated with the difference in that meet the discounted cash flow model of the basic assumptions, the relationship between free cash flow and enterprise value of listed companies high. He thinks, Guo Yan (2015) thinks that when using the free cash flow model to evaluate the enterprise value, we should not only pay attention to the analysis of financial index, but also pay attention to the influence of non-financial indicators on the prediction of the free cash flow of enterprises. Yun Dandan (2014) applies the weighted cost method of the free cash flow discount method to estimate the value of Qingdao Haier. Based on the assumption that the value remains unchanged and the capital structure of enterprises remains unchanged, the market value of Haier at the end of 2014 is obtained. Liu Yajie (2016) based on the free cash flow model, the value of a A enterprise is evaluated and predicted by.

Foreign scholars Mohsen Dastgir, ValiKhodadadi and Maryam Ghayed (2010) studied the discounted cash flow method of enterprise value assessment and found that the use of a suitable discount rate has a great impact on the capital cash flow, and the final valuation of the enterprise can also be large Influence. Carlos Acosta Calzado (2011) used the discounted cash flow method to evaluate the value of Mexican sugar mills and conducted a sensitivity analysis of the factors that affect the value of sugar mines. Redhwan Ahmed AL-Dhamari, Ku Nor Izah Ku Ismail (2014) studied the effective governance of firms to improve the company's valuation and the free cash flow of firms, and explored the prediction that earnings free cash flow of corporate earnings can affect returns. 
According to the domestic and foreign scholars' research, it is more inclined to use free cash flow to evaluate the enterprise value. Therefore, this article also selects the free cash flow method to evaluate the enterprise value of Bei Xin Yuan Information Technology Co, Ltd.

\section{Enterprise Value Evaluation System Based on FCFF Model}

(1) FCFF discounted method. The free cash flow of an enterprise is the cash flow generated by the enterprise after the investment needs are satisfied. This part of the cash flow is the maximum cash available for distribution to the enterprise without affecting the sustainable development of the enterprise. Simply put, free cash flow is the cash flow generated by operating activities, excluding capital expenditures after the difference.

The formula is: enterprise free cash flow $(\mathrm{FCFF})=$ Pre tax profit $(\mathrm{EBIT}) *(1$ tax rate $\mathrm{T})+$ depreciation and amortization - changes in working capital - capital expenditure.

Calculation of enterprise value. This paper selects a two-stage cash flow discount model, the basic formula is as follows:

$$
\mathrm{V}=\sum_{t=1}^{t=n}{\frac{F C F F_{t}}{(1+W A C C)^{t}}}^{t}+\frac{P_{n}}{(1+W A C C)^{n}}
$$

Where: $\mathrm{n}$ - value of the assessment period of a clear forecast period; WACC - the base period of the weighted average cost of capital; Pn - enterprises clear forecast after the continuous value; FCFFt - the expected free cash flow for period t.

The basic assumption in the model: First, the firm's operating condition is stable and the capital structure is not changed; Second, there will be no major changes in the related systems, such as tax and law, and the risk of operation can be correctly predicted.; Third, there will be no significant change in the income of the enterprise's main business, and the future income can be measured in currency; Fourth, business continuity.

\section{The Enterprise Value Evaluation of Beixinyuan Company}

\subsection{The Prediction of Free Cash Flow in Enterprises}

\subsubsection{The Forecast of Related Financial Data}

Beijing North letter Source Software Co., Ltd. (North letter source VRV), founded in 1996 with a registered capital of 133.4 million, in 2012 in the Shenzhen Stock Exchange (stock code: 300352). The company is in the software industry and is a national-level high-tech enterprise specialized in information security. Its main business is research and development, production, sales and provision of technical services for information security software products.

The influence factors of enterprise free cash flow mainly includes the following points: one is the main business revenue growth, which is forecast for the main business of their own; the two is the relevant financial data accounting for the main business income ratio, so the determination of these financial data accounted for the main business income is very important. The specific calculation is shown in Table 1.

Table 1 Beixinyuan 2012-2015 financial data accounted for the percentage of main business income.

\begin{tabular}{ccccc}
\hline Year & 2012 & 2013 & 2014 & 2015 \\
\hline Profit ratio & $35.82 \%$ & $29.74 \%$ & $28.22 \%$ & $16.53 \%$ \\
Financial cost ratio & $-1.37 \%$ & $-3.24 \%$ & $-3.47 \%$ & $-1.28 \%$ \\
Depreciation and amortization ratio & $6.11 \%$ & $7.65 \%$ & $11.05 \%$ & $8.21 \%$ \\
Working capital increase ratio & $44.84 \%$ & $41.49 \%$ & $28.29 \%$ & $11.73 \%$ \\
Capital expenditure ratio & $0.20 \%$ & $0.81 \%$ & $11.95 \%$ & $17.69 \%$ \\
\hline
\end{tabular}

Data source: Beixinyuan 2011-2015 Annual Report

Expected main business income

According to 2011-2015 annual report of the enterprise can be calculated as Table 2 and Figure 1: 
Table 2 The growth rate of main business income of Beixinyuan in 2011-2014

\begin{tabular}{c|c|c|c|c}
\hline Year & 2012 & 2013 & 2014 & 2015 \\
\hline Growth rate of main business income & $49.63 \%$ & $20.13 \%$ & $15.13 \%$ & $78.89 \%$ \\
\hline
\end{tabular}

Data source: Beixinyuan 2011-2015 Annual Report

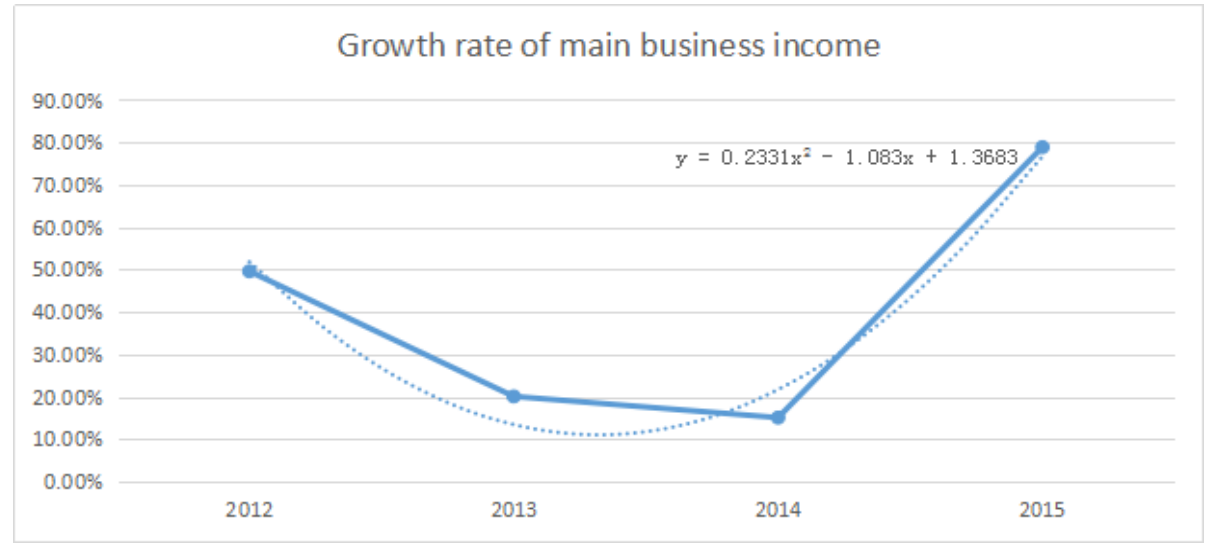

Figure 1 Growth rate of main business income of Beixinyuan in 2012-2015 Data source: Beixinyuan 2011-2015 Annual Report

According to the trend of Figure 1, for the third quarter report of Beixinyuan, the core business growth rate of Beixinyuan reached $34.55 \%$ in the third quarter of 2016. According to the information of Beixinyuan's 2016 semi-annual report, the company's main business Revenue growth rate of $34.58 \%$, in the first quarter report, total revenue of up to $36.16 \%$, so as to predict 2016 Beixinyuan main business revenue growth rate of $50 \%, 2017$ forecast is $20 \%, 2018$ forecast is $15 \%, 2019$ forecast value of $20 \%, 2020$ forecast value of $70 \%$.

Table 3 Main business income forecast (Unit: RMB)

\begin{tabular}{c|c|c|c|c|c}
\hline Year & 2016 & 2017 & 2018 & 2019 & 2020 \\
\hline $\begin{array}{c}\text { Main business } \\
\text { income }\end{array}$ & 799025500 & 1038733150 & 1246479780 & 1620423714 & 2119015626 \\
\hline
\end{tabular}

(2) Expected total profit

From table 1, it can be seen that the total profit of 2012-2015 years is $35.82 \%, 29.74 \%, 28.22 \%$, $16.53 \%$. We can see that the profit ratio of the enterprise has been in a downward trend, it is expected that the total profit of 2015-2019 years accounted for the proportion of main business income for the average of $27.6 \%$, calculate the total profit of 2016-2020 years were 194434463.5 yuan, 233321356.3 yuan, 268319559.7 yuan, 321983471.6 yuan, 456143251.5 yuan.

(3) Expected financial expenses

From Table 1, we can see that the proportion of finance costs in 2012-2015 in the main business revenue is in a state of volatility. Therefore, assuming that the financial expenses in 2016-2020 will account for $-2.3 \%$ of the main business revenue, the costs are: -16502932.1 yuan, -19803518.53 yuan, -22774046.3 yuan, -27328855.57 yuan, -38715878.72 yuan.

(4) Expected depreciation and amortization.

The proportion of depreciation and amortization as main business income in 2012-2015 is: $6.11 \%$, $7.65 \%, 11.05 \%, 8.21 \%$, and the average value of the four years is $8.25 \%$.

(5) Expected increase in working capital

From 2012 to 2015, the increase of working capital accounted for $44.84 \%, 41.49 \%, 28.29 \%$ and $11.73 \%$ of the main business revenue, which has been declining. Therefore, $8 \%$ is taken as the increase of working capital.

(6) Expected capital expenditures

From 2012 to 2015 , capital expenditures accounted for $0.2 \%, 0.81 \%, 11.95 \%$ and $17.69 \%$ of the main business revenue respectively. The overall trend is still on an upward trend. It is expected that the ratio of capital expenditure to main business income in 2016-2020 will be $7.6 \%$ of the average for 2012-2015. 


\subsubsection{The Future Free Cash Flow of Enterprises}

According to the proportion of the above expected related financial data to the main business income, the future free cash flow of Beixinyuan can be obtained. The calculation process is shown in Table 4.

Table 4 Forecast table of free cash flow of beixinyuan in 2016-2020 (Unit: RMB)

\begin{tabular}{cccccc}
\hline Year & 2016 & 2017 & 2018 & 2019 & 2020 \\
\hline Main business income & 799025500 & 1038733150 & 1246479780 & 1620423714 & 2119015626 \\
profit & 220359058.7 & 286466776.3 & 343760131.6 & 446888171 & 584392223.6 \\
Less: financial costs & -18703323.05 & -24314319.97 & -29177183.96 & -37930339.15 & -49601212.73 \\
Ebit & 239062381.7 & 310781096.3 & 372937315.5 & 484818510.2 & 633993436.4 \\
$\quad \begin{array}{c}\text { Ebit*(1-15\%) } \\
\text { Add: depreciation and }\end{array}$ & 203203024.5 & 264163931.8 & 316996718.2 & 412095733.6 & 538894420.9 \\
$\quad$ amortization & 65961043.53 & 85749356.59 & 102899227.9 & 133768996.3 & 174928687.4 \\
Less: working capital & 63922040 & 83098652 & 99718382.4 & 129633897.1 & 169521250.1 \\
$\quad$ increased & & & & & \\
Less: capital expenditure & 34956722.33 & 45443739.02 & 54532486.83 & 70892232.88 & 92705227.61 \\
Enterprise free cash flow & 170285305.7 & 221370897.4 & 265645076.9 & 345338599.9 & 451596630.7 \\
\hline
\end{tabular}

\subsection{Enterprise Value Evaluation}

\subsubsection{The Forecast of Weighted Average Capital Cost}

(1) the determination of the capital structure

According to the company's annual report 2011-2014, the company does not have long-term debt and short-term debt, so the company's capital structure is shown in Table 5:

Table 5 the capital structure of Beixinyuan

\begin{tabular}{ccccc}
\hline & 2012 & 2013 & 2014 & 2015 \\
\hline Debt capital (yuan) & 0 & 0 & 0 & 0 \\
Equity capital (yuan) & 592296000 & 646990000 & 701684000 & 837700984.4 \\
Total capital (yuan) & 592296000 & 646990000 & 701684000 & 837700984.4 \\
Debt proportion & 0 & 0 & 0 & 0 \\
Share of equity & $100 \%$ & $100 \%$ & $100 \%$ & $100 \%$ \\
\hline
\end{tabular}

Therefore, the capital cost of a company does not have a debt capital cost, and the cost of the company's equity capital is the cost of the company's capital.

(2) the cost of equity capital

(1)Risk-free rate of return

The rate of risk-free returns is usually expressed by the interest rate of the national debt. But for our country, the interest rate of national debt is not representative. Therefore, the interest rate of bank deposit is usually used as a risk free rate. This paper selects the one-year bank deposit rate published by the central bank as a risk-free rate of return. The one-year bank deposit rates for 2012-2015 years are $3 \%, 3 \%, 3 \%, 2.5 \%$.

(2) Market risk premium

Market risk premium ( $R m-R f$ ) is equal to the expected rate of return of market portfolio minus risk free return rate, which is a part of the expected return rate of investors who exceed the risk-free rate of return when they invest. The North source is listed on the Shenzhen gem, so the average return of the gem comprehensive index is selected to calculate the expected earnings. The specific calculation is shown in Table 6.

(3) Beta coefficient

The value calculated in this paper is obtained through the Wind data query. The adjusted value of 2012-2015 is $0.8074,1.1426,1.4589$ and 1.4150 .

(4) equity capital costs

Since the GEM composite index only had a short period of time in 2010, this paper uses the 2014 risk premium as a risk premium over the historical years. Specific calculation as shown in Table 7. 
Table 6 market risk premium

\begin{tabular}{ccccc}
\hline & 2012 & 2013 & 2014 & 2015 \\
\hline Gem composite index & 725.78 & 711.942 & 1243.96 & 1580.373 \\
Annual rate of return & & $-1.91 \%$ & $74.73 \%$ & $27.04 \%$ \\
Average annual rate of return & & $-1.91 \%$ & $36.41 \%$ & $50.89 \%$ \\
Risk-free rate of return & $3.00 \%$ & $3.00 \%$ & $3.00 \%$ & $2.50 \%$ \\
Market risk premium & & $-4.91 \%$ & $33.41 \%$ & $47.89 \%$ \\
\hline
\end{tabular}

Table 7 cost of equity capital

\begin{tabular}{ccccc}
\hline Year & 2012 & 2013 & 2014 & 2015 \\
\hline Risk-free interest rate & $3.00 \%$ & $3.00 \%$ & $3.00 \%$ & $2.50 \%$ \\
Beta coefficient & 0.8074 & 1.1426 & 1.4589 & 1.415 \\
Market risk premium & $13.36 \%$ & $13.36 \%$ & $13.36 \%$ & $13.36 \%$ \\
Cost of equity capital & $11.36 \%$ & $14.84 \%$ & $18.11 \%$ & $17.87 \%$ \\
\hline
\end{tabular}

Since the company's cost of equity capital is the weighted capital cost of the company, the average cost of equity capital for 2012-2015 years is $15.55 \%$. That is, the cost of weighted capital is $15.55 \%$.

\subsubsection{The Calculation of Enterprise Value}

The weighted capital cost for the future period of this paper is the average of weighted capital cost from 2012 to $2015: 15.55 \%$. In this paper, the two-stage growth model is adopted, and the trend of stable growth after five years is adopted, and the GDP growth rate is $6.7 \%$. The free cash flow of the above enterprises in the next five years is: 170285305.7 yuan, 221370897.4 yuan, 265645076.9 yuan, 345338599.9 yuan, 451596630.7 yuan.

The calculation of enterprise value is as follows:

$$
\begin{aligned}
& V=\frac{170285305.7}{(1+15.55 \%)}+\frac{221370897.4}{(1+15.55 \%)^{2}}+\frac{265645076.9}{(1+15.55 \%)^{3}}+\frac{345338599.9}{(1+15.55 \%)^{4}}+\frac{451596630.7}{(15.55 \%-6.7 \%) \times(1+15.55 \%)^{4}} \\
& =3541449663(\text { yuan })
\end{aligned}
$$

Equity value $=$ enterprise value - debt value $=3541449663$ (yuan)

In 2015 , the company issued 270226124 shares of stock, so the stock price was calculated to be 13.11 yuan, and the issue price in 2015 was 23.35 yuan / share, which is higher than the calculated stock price. The average value of 2015 stock is 23.94 yuan, which is also higher than the calculated theoretical price. By the end of April 5, 2017, the closing price of Beixinyuan was 17 yuan.

\section{Conclusion}

Based on a comprehensive analysis of Beixinyuan annual report of 2011-2015 and access to a large number of documents and data, this paper evaluates Beixinyuan enterprise value by free cash flow discounting, and draws the following conclusions:

First: the current development of Beixinyuan enterprises in general, can take a wait-and-see attitude. The software and technology service industry is in a stage of development in China, and our government is an encouraging attitude towards its development, and the future development prospect is better. However, Beixinyuan enterprises are still in the growth stage and mainly serve the government and military industries. The profits of enterprises are mainly used to pay dividends to shareholders, and the return on common stock is less.

Second: in this paper, the calculation of the VRV enterprise value for the enterprise value in 2015, in this point, the evaluation of stock value is lower than the stock price, therefore does not favor the stock, investors can choose to wait, when it continues to expand, consider whether to buy. 
The deficiency of this paper lies in that the enterprise listed years shorter, so the data is relatively lack, to the enterprise's future free cash flow forecast has certain subjectivity, enterprises face the future environment is complex and changeable, so the rationality of the data predicted by the further inspection. At the same time, only rely on the statements provide data to predict net operating profit after tax depreciation and amortization of influence on enterprise value assessment, and therefore should be combined with the enterprise's future development situation of these elements for further analysis.

\section{Acknowledgements}

Project supported by the National Social Science Foundation of China (Grant No.15ZDC022, 17BGL209); National Natural Science Foundation of China (Grant No.71373199, 71703033).

\section{References}

[1]. Tan Hanmei. Enterprise value evaluation based on free cash flow discount model[J]. Internal Auditing in China, 2016,0 2: 96-101.

[2]. Sun Yanhua. Research on the application of free cash flow discount model in enterprise value evaluation[J]. Economic \& Trade, 2016, 07: 76.

[3]. Chuanlian Song. Problems and Countermeasures on Enterprise Value Assessment in China[J]. International Journal of Business and Management, 2010, 510.

[4]. Redhwan Ahmed AL-Dhamari, Ku Nor Izah $\mathrm{Ku}$ Ismail. An investigation into the effect of surplus free cash flow, corporate governance and firm size on earnings predictability[J]. International Journal of Accounting and Information Management, 2014, 22(2): 118-133.

[5]. Zhang Zhenhua. Research on the value evaluation of e-commerce enterprises[J]. Communication of Finance and Accounting,2017(26):73-76. 